\title{
Broad Ligament Serous Cystadenoma
}

National Cancer Institute

\section{Source}

National Cancer Institute. Broad Ligament Serous Cystadenoma. NCI Thesaurus. Code C126476.

A rare serous cystadenoma arising from the broad ligament. 